\title{
Proposed Measures to Protect Temporary Roofs from Unwanted Heat Gains
}

\author{
Omar S. Asfour \\ Department of Architecture, Islamic University of Gaza, The Palestinian Territories, PO Box 108, Gaza \\ e-mail: oasfour@iugaza.edu.ps
}

Cite as: Asfour, O. S., Proposed Measures to Protect Temporary Roofs from Unwanted Heat Gains, J. sustain. dev. energy water environ. syst., 5(2), pp 191-201, 2017, DOI: http://dx.doi.org/10.13044/j.sdewes.d5.0142

\begin{abstract}
This study focuses on the uncompleted multi-storey residential buildings located in hot climates. This construction pattern is common in the case of incremental housing, where additional floors are added to the building as housing needs grow. Top roofs in these buildings are usually left without thermal insulation until the rest of upper floors are erected. This causes higher thermal discomfort in the top flats compared to the lower ones. Thus, the aim of this study is to investigate thermal effect of some proposed temporary measures that are intended to protect these roofs from unwanted heat gains until the rest of storeys are constructed. This has been carried out using thermal modelling to find out the effect of these measures on the amount of heat transfer through the roof in both summer and winter times. The analysis showed that it is possible to achieve competent thermal protection of the top roof compared to the layered thermal insulation using simple, cost-effective, and reversible measures. Among the examined measures, covering the roof with white foldable sheets and the use of pergolas have been found to be the most effective measures. In both cases, a reduction of $38 \%$ in conductive heat transfer through the top roof in summer was observed compared to the unprotected modelling case.
\end{abstract}

\section{KEYWORDS}

Buildings, Hot climates, Thermal insulation, Temporary roofs, Thermal modelling.

\section{INTRODUCTION}

The concerns over the depletion of non-renewable energy sources have prompted increasing research efforts in the field of sustainable architecture. Sustainable architecture is a major component of the wider frame of sustainable development. This concept is clearly expressed in the famous Brundtland definition, which states that sustainable development is "development that meets the needs of the present without compromising the ability of future generations to meet their own needs" [1]. This concept shows the essential role of sustainable architecture considering the great amount of resources consumed in the construction and operation of buildings. It is generally estimated that about $50 \%$ of all resources globally consumed goes to the construction sector [2]. Sustainable architecture necessitates that buildings should be energy efficient. This means that energy consumption in buildings should be rationalised. Among the techniques used in this regard is thermal insulation. Air conditioners began to spread in the 1970's. Since then, their efficiency significantly improved as a result of the 
technological developments [3]. However, the use of passive thermal design techniques such as thermal insulation remains the first option for designers.

Thermal insulation is one of the most effective measures that help in improving energy efficiency in buildings. The main aim of thermal insulation is to protect building envelope from any unwanted heat transfer from/to the building. Heat transfer through building envelope components can be controlled by the choice of appropriate materials. These materials usually have high resistance $R$, to heat transfer from outside to inside and vice versa. This technically means that these elements have low thermal conductance coefficients, known as $U$-value or $U$-factor. This is the heat flow density $\left(\mathrm{W} / \mathrm{m}^{2}\right)$ with $1 \mathrm{~K}$ temperature difference between air inside and air outside a building envelope element, e.g. a wall, measured in $\mathrm{W} / \mathrm{m}^{2} \mathrm{~K}$ [4]. The main heat transfer process for solid, opaque building elements occurs by conduction. This occurs as a result of the fast molecular movement induced by heat in solid objects. Thus, elements of building envelope including external walls, roofs, floors, and windows are all possible routes of this heat transfer. These elements should be protected using well-designed thermal insulation to prevent them acting as weak links or thermal bridges in the building [5]. In any of these elements, such as the roof, conductive heat flow $(Q)$ in Watts depends on the overall exposed surface area of a building material $(A)$, its $U$-value $(U)$, and temperature difference between inside and outside $(\Delta T)$ in Kelvin. These are given in the following simple equation:

$$
Q=A \times U \times \Delta T
$$

Despite the fact that thermal insulation is useful for all building envelope elements, roofs deserve more attention in this regard. Roofs receive a great deal of incident solar radiation. This is because roofs are constantly exposed to solar radiation between sunrise and sunset. This becomes more significant when the roof is horizontal or when its area is large compared to the external area of the building. It is estimated that $60 \%$ of the gross thermal transfer in buildings occurs through the roof [6]. Several strategies are used to provide thermal insulation for the final roofs. This includes the use of typical layered insulators such as polystyrene [7], the use of green roofs [8], the use of white painting [9], and the use of moving air cavities [10].

Several studies have been carried out to investigate the role of thermal insulation to protect buildings from unwanted heat gains. Alrashed and Asif [11] investigated some factors that are related to the residential energy consumption with reference to Saudi Arabia. These factors included weather conditions, types of dwellings, building envelops, air-conditioning systems, and domestic appliances. A survey was carried out to analyse the actual monthly electricity consumption in a sample of dwellings. The annual average electricity consumption for the surveyed dwellings was found to be higher than the standard value. The study recommended that the use of mini-split $\mathrm{A} / \mathrm{C}$ systems, thermal insulation and double-glazed windows are major factors that help reduce this consumption by about $30 \%$. Tettey et al. [12] calculated the effect of various insulation materials on energy consumption and Carbon dioxide $\left(\mathrm{CO}_{2}\right)$ emission in residential buildings. The study examined a variety of insulation materials in a reference building including mineral rock wool, glass wool, cellulose fiber, and expanded polystyrene. Results showed a reduction of about 6-7\% in primary energy use and 6-8\% in $\mathrm{CO}_{2}$ emission when the insulator in the reference buildings was changed from rock wool to cellulose fiber. This study recommended concluded that renewable-based materials can effectively contribute to energy savings and GHG emission reduction.

Bevilacqua et al. [13] carried out an experimental investigation to find out the effect of roof thermal insulation coupled with different vegetation strategies on the roof thermal performances. This was done considering the Mediterranean climatic conditions. The analysis showed that the investigated green roof was able to reduce the summer 
temperature at the interface with the structural roof by $12{ }^{\circ} \mathrm{C}$ on average. In winter, the roof was able to maintain a value that is $4{ }^{\circ} \mathrm{C}$ higher on average. Asfour and Kandeel [7] carried out a study of thermal performance modelling with reference to thermal insulation. The study considered multi-storey residential buildings located in hot climates as a main focus, where thermal insulation of external walls and roofs has been examined. This was done using two types of thermal insulators. The numerical assessment carried out revealed that the good use of thermal insulation in walls and roofs can effectively reduce undesired heat gains and losses through building fabric, which help reducing human discomfort throughout the year by about $17 \%$.

It could be noticed that thermal insulation as a strategy of sustainability in buildings is a common research topic. However, this study tackles the issue of thermal insulation considering the case of temporary roofs, which is not a common topic in the literature. The research question is how to protect temporary roofs in multi-storey buildings from unwanted heat transfer. These roofs are not permanent, and thus not insulated using permanent thermal insulation. Uncompleted multi-storey buildings are common in housing sector, and could be commonly noticed in the urban environments of developing countries. This is because construction of multi-storey residential buildings in these environments has an incremental nature to serve the extended family social pattern [14]. This means that as the family grows, the building grows too. Thus, this study focuses on the thermal protection of these uninsulated temporary roofs.

This is done with reference to the hot climate of the Gaza Strip, Palestine. The Gaza Strip is characterised by a crowded urban environment as a result of its limited area $\left(365 \mathrm{~km}^{2}\right)$. Its population is estimated at 1.88 million inhabitants [15], with a density of 4,661 person $/ \mathrm{km}^{2}$ compared to 481 person $/ \mathrm{km}^{2}$ in the West Bank, the northern governorates of Palestine [16]. This high density resulted in a rapid increase in housing land price [17]. As a result, green areas decreased and the use of air conditioning has become a common practice. Unfortunately, the use of thermal insulation is not a common practice in the residential buildings of Gaza. People in Gaza tend to build their houses in the form of multi-storey apartment buildings. As mentioned above, these apartment buildings are usually built according to the inhabitants' present need. It is a common practice that they do not build up to the maximum allowed height, which results in uncompleted housing blocks. This causes several problems such as the uncompleted facades, the unfinished exterior, and the uninsulated top roof. Taking the latter problem as a focus of this paper, the top floor in this case usually suffers from excessive heat gains in summer and excessive heat losses in winter [7]. The usual treatment is to apply thermal insulation to this roof. However, it is a challenge to do so given that it is a "temporary" roof. Thus, this paper aims at investigating this research problem through the modelling of several possible solutions as explained in the "Research method".

\section{RESEARCH MATERIALS AND METHODS}

This paper aims to investigate the effect of some proposed measures to protect the temporary roofs of multi-storey buildings from unwanted heat gains in summer and unwanted heat losses in winter. This is done with reference to the hot climate in the Gaza Strip, Palestine. A numerical modelling has been carried out using the computerised simulation. This modelling is particularly useful as it facilitates examining several design alternatives and provides numerical performance assessment based on predefined indicators. These proposed measures have been selected based on a field observation to find out the common practices in this regard. The following roof protection measures were concluded:

- Painting using white paint;

- Tiling using dark or light colour tiles; 
- Shading using pergolas;

- Shading using normal or high parapet;

- A combination of two or more strategies.

It is also possible to combine several strategies in this regard. For example, several studies such as Brito and Santos [9], Ramamurthy et al. [18], and Arumugam et al. [19] found that in hot climates, roofs with combined thermal insulation and reflective coating is the best option. This combination could significantly reduce thermal insulation thickness and thus reduce the cost and maximise energy savings. Numerical modelling in this study is carried out using Ecotect program. This program is a common tool used for conceptual thermal design. It helps designers to choose the best alternative in the early design stage to secure better thermal performance [20]. This is consistent with the nature of this study, which examines the preliminary effect of several thermal protection strategies of temporary roofs. However, to obtain precise results, field measurements are recommended to validate the simulation findings.

Ecotect offers several indicators of thermal performance, including heat gains and losses analysis. Quantifying heat gains and losses for any defined thermal zone helps designers to diagnose and treat unwanted heat transfer type. This includes heat transfer between thermal zones, heat transfer due to ventilation, internal loads and occupancy, solar exposure, and conduction. Given that heat transfer via conduction is the main focus of the current conceptual study, heat gains and losses through the temporary roof measured in $\mathrm{kWh}$ have been recorded. Factors that affect thermal conduction are presented in equation 1 in the previous section. Considering that roof exposed area and temperature difference are constants, variables of this study could be perceived as follows: thermal properties of the roof as an independent variable, and summer heat gains and winter heat losses through the roof as a dependant variable. Thermal properties that are varied in the different examined protection strategies are as follows [21]:

- $U$-value (or Transmittance), which is varied as a result of changing roof layers. $U$-value is measured in $\mathrm{W} / \mathrm{m}^{2} \mathrm{~K}$, where lower $U$-value means less conduction and better insulation;

- Thermal lag (or Time lag) is the time required for heat to flow from one side of the building envelope element to the other. It is measured in decimal hours depending mainly on the $U$-value;

- Solar absorption is a factor that varies between 0 and 1 . It reflects the amount of incident solar radiation that is absorbed by a surface, the roof here. This has been varied through the alteration of roof colour.

In general, thermal simulation has been carried out considering the following geometrical and thermal settings (Figure 1):

- A five-storey naturally ventilated residential building is assumed;

- Each floor includes two flats. Flat area is assumed $85 \mathrm{~m}^{2}$. The top flats are only analysed;

- Each flat is assumed as a single thermal zone that accommodates 5 users in sedentary status;

- Sensible gains are assumed $10 \mathrm{~W} / \mathrm{m}^{2}$. Infiltration rate is assumed $0.5 \mathrm{ACH}$;

- $U$-values of building elements are selected to match the commonly used materials in Gaza. This is shown in Table 1.

The building was firstly modelled without any thermal protection of the top roof, which presents the reference case. The building then was modelled with a typical layered thermal insulation of the final roof using polystyrene boards, which presents the optimum case. $U$-value of the insulated roof in these cases ceased from 2.19 to $0.76 \mathrm{~W} / \mathrm{m}^{2} \mathrm{~K}$. Then, the proposed protection measures were implemented and their effect on the building thermal performance was recorded. The main parameter in evaluating the thermal 
performance of the different proposed measures is the reduction of heat gains through the fabric (the opaque elements of roof and external walls). Given that the proposed measures are only implemented on the roof, any change in the fabric heat transfer should occur in the roof, since no changes were implemented to the external walls properties.
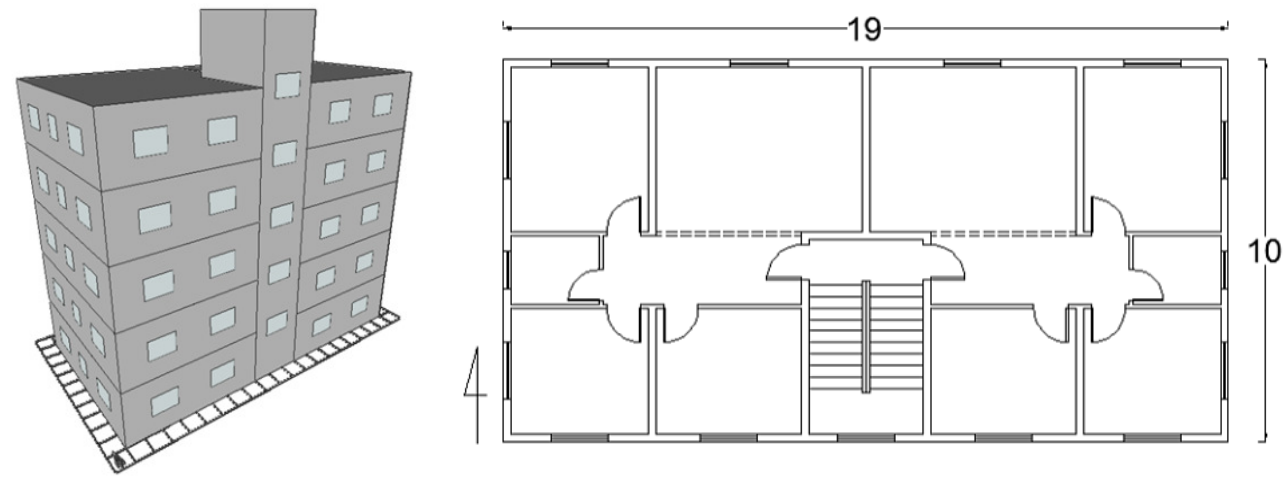

Figure 1. Perspective and plan of the reference modelling case

Table 1. Thermal properties of building materials used in the reference modelling case

\begin{tabular}{cccc}
\hline Element & Description & $U$-value $\left[\mathrm{W} / \mathrm{m}^{2} \mathrm{~K}\right]$ & Thermal lag [hrs] \\
\hline Walls & Concrete blocks with cement plaster & 1.69 & 5 \\
Windows & Single glazed with aluminium frame & 6.0 & N/A \\
Ceilings & $25 \mathrm{~cm}$ concrete slab covered with tiles & 1.85 & 6.8 \\
Final roof & $25 \mathrm{~cm}$ concrete slab & 2.19 & 6.8 \\
\hline
\end{tabular}

\section{RESULTS AND DISCUSSION}

In Ecotect, the hourly heat gains/losses graphs display the magnitude of all the different heat flow paths in the building. These are displayed over a 24-hour period for any day in the year. This includes conduction loads through the fabric, which is our focus in this study. Given that external walls' conditions are not varied, the observed change in the fabric heat transfer should be related to the different proposed roof protection strategies. The average hottest day is used to represent the summer time, and the average coldest day is used to represent the winter time. Figure 2 shows the obtained results. It shows the average daily summer heat gains and winter heat losses through the top roof for the western flat (top) and the eastern one (bottom) considering different protection strategies. In general, no significant difference is observed between the two top flats. However, heat gains through the top floor of the eastern flat are slightly less than the western one. This could be attributed to the shading effect of the staircase, which is extruded for an additional floor above the final roof. The shadow of the staircase covers a significant area of the top roof of the eastern flat when the sun moves towards the west. This is supported by the fact that heat losses through the top floor of the eastern flat are slightly higher than the western one. This true for all the strategies examined in this study. Thus, the rest of discussion will be limited to the western flat.

\section{Full roof insulation strategy}

It could be noticed in Figure 2 that the best reduction of the unwanted heat gains/ losses through the top roof is observed in the fully insulated roof case. The $25 \mathrm{~cm}$ slab in this case is protected using the following layers: $5 \mathrm{~cm}$ of polystyrene boards, $5 \mathrm{~cm}$ of foam concrete, $2.5 \mathrm{~cm}$ water proofing, $2.5 \mathrm{~cm}$ of sand, and $2.5 \mathrm{~cm}$ of cement mortar and ceramic tiles. $U$-value of the insulated roof ceased from 2.19 to $0.76 \mathrm{~W} / \mathrm{m}^{2} \mathrm{~K}$. As a result, 
the average daily fabric gains in summer decreased from $50.1 \mathrm{~kW} / \mathrm{h}$ in the reference case to $21.3 \mathrm{~kW} / \mathrm{h}$ in the fully-insulated case. This means a reduction of about $57 \%$. In winter, a significant reduction is observed too. Average daily heat losses decreased from $-42.8 \mathrm{~kW} / \mathrm{h}$ in the reference case to $-27.2 \mathrm{~kW} / \mathrm{h}$ in the fully-insulated case. This means a reduction by about $35 \%$. The observed improvement is much higher in summer since the prevailing climate in the study area is the hot climate.

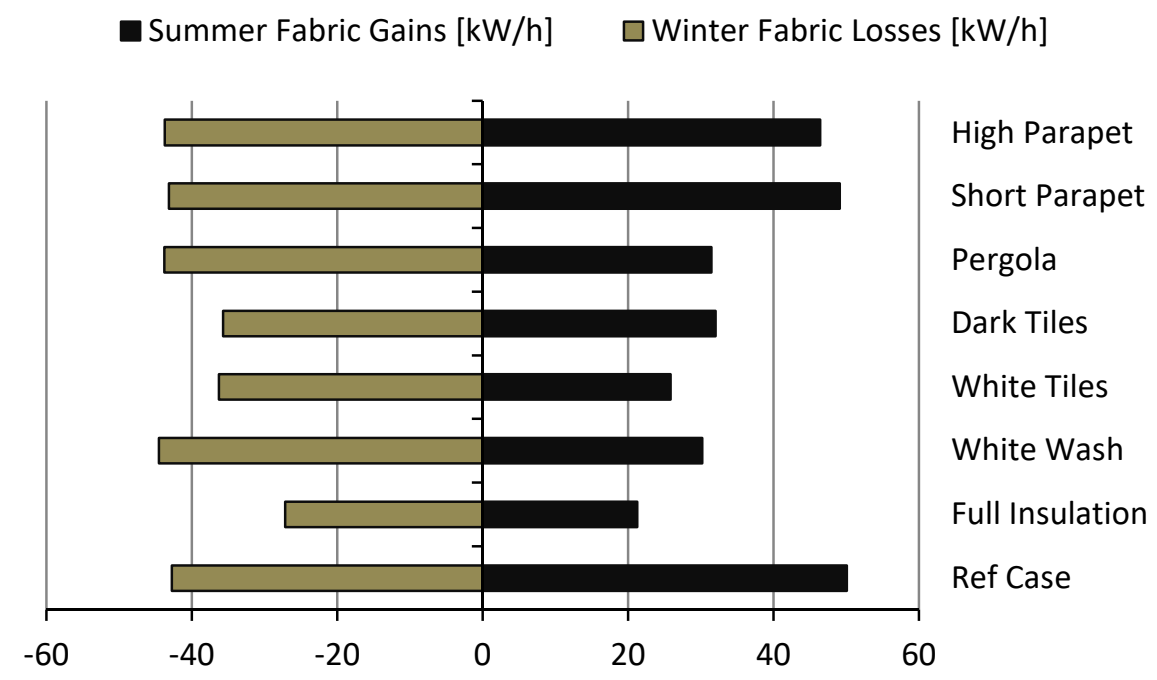

Summer Fabric Gains [kW/h] $\quad \square$ Winter Fabric Losses [kW/h]

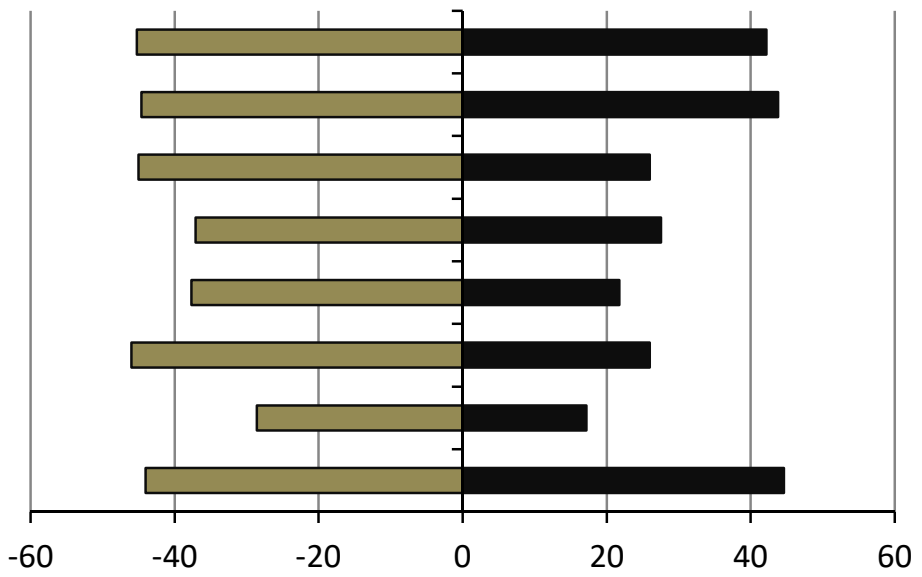

High Parapet

Short Parapet

Pergola

Dark Tiles

White Tiles

White Wash

Full Insulation

Ref Case

Figure 2. Average daily summer heat gains and winter heat losses through building fabric for the western flat (top) and the eastern one (bottom) considering different roof protection strategies

\section{Roof painting strategy}

As argued in the research method, full roof insulation is usually not implemented in Gaza due to the fact that multi-storey buildings are usually constructed incrementally. Thus, temporary protection strategies are more favoured in this case. The first strategy is the use of white paint/cladding that is applied directly to the uninsulated roof slab. This strategy means that solar absorption of the roof was reduced from 0.9 to 0.1 . This in fact has been found to have the most significant effect considering that no additional insulation layers are applied to the roof. This is in agreement of Filho and Santos [9] findings, which suggested that for subtropical climates, the application of white paint on a roof that has no additional layers for thermal insulation is the best solution to reduce energy consumption. 
As shown in Figure 2, the average daily fabricgains in summer decreased from $50.1 \mathrm{~kW} / \mathrm{h}$ in the reference case to $30.2 \mathrm{~kW} / \mathrm{h}$ in the case of roof painting. This means a reduction of $39 \%$. In winter, no significant change was observed. This means that the benefit of this strategy is limited to the summer period since white paint is applied to the external layer of the roof and has nothing to do with the heat escaping from the interior through the roof. A possible alternative to assist the solar radiation to warm up the roof in winter is the use of white sheets in summer that could be removed in winter time.

\section{Roof tiling strategy}

The use of white tiles is based on the same concept of the white painting strategy. However, it secures additional layers of sand, cement mortar, and ceramic tiles upon the roof which ensures better thermal protection. This reduces $U$-value of the roof from 2.2 to $1.8 \mathrm{~W} / \mathrm{m}^{2} \mathrm{~K}$. Also, solar absorption of the roof was reduced from 0.9 to 0.1 . This strategy looks very effective and secures the best protection compared to the rest of strategies (with the exception of full insulation strategy). However, it includes some costs that may not be appropriate for the protection of temporary roofs (this is discussed at the end of the study). As shown in Figure 2, the average daily fabric gains in summer decreased from $50.1 \mathrm{~kW} / \mathrm{h}$ in the reference case to $25.9 \mathrm{~kW} / \mathrm{h}$ in the case of using white tiling. This means a reduction of $48 \%$. In winter, a significant reduction is observed too. Average daily heat losses decreased from $-42.8 \mathrm{~kW} / \mathrm{h}$ in the reference case to $-36.3 \mathrm{~kW} / \mathrm{h}$ in the case of using white tiling. This means a reduction of $15 \%$. The use of dark tiles reduces $U$-value, but not solar absorption factor of the roof. Thus, the observed reduction in fabric gains has declined from $48 \%$ to $36 \%$.

\section{Roof shading using pergolas}

This strategy offers a horizontal shading element that stretches over the top roof (Figure 3). As there is no contact between the pergola and the roof, conductive heat transfer value is independent of the pergola's $U$-value. Pergolas can be constructed using clay tiled roofs, membranes, or panels. As shown in Figure 2, the average daily fabric gains in summer decreased from $50.1 \mathrm{~kW} / \mathrm{h}$ in the reference case to $31.5 \mathrm{~kW} / \mathrm{h}$ in the whitewash case. This means a reduction of $37 \%$. In winter, average daily heat losses slightly increased from -42.8 to $-43.7 \mathrm{~kW} / \mathrm{h}$. This shows that the effect of using pergolas on conductive heat transfer through the roof is quite similar to the use white painting. However, to benefit from solar radiation in winter, it is recommended to use foldable pergolas that are easily removed during winter seasons. Figure 3 shows the resulting incident solar radiation (insolation) on the roof at noon time of an average summer day. It is clear that the majority of the roof receives low insolation levels $(210 \mathrm{Wh})$ as a result of the implemented shading strategy.
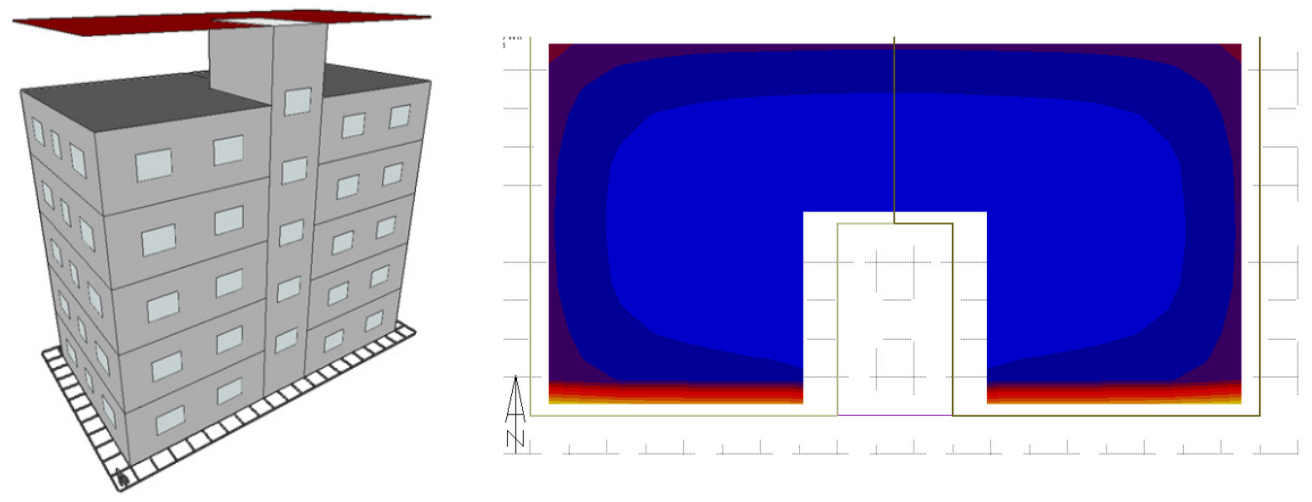

Figure 3. Roof shading using a pergola (left) and the resulting insolation on an average summer day at noon time (right) 


\section{Roof shading using parapets}

A parapet is a barrier which forms a protection for roof users. In Gaza, flat roofs are used in the residential buildings, where parapets are constructed in the form of $1.2 \mathrm{~m}$ solid walls. Another less common option is to extrude this wall up to the full floor height, i.e. $3 \mathrm{~m}$. The prospective windows are usually opened in this wall as voids. Both options are examined here (Figure 4). Figure 2 shows that normal parapets have almost no effect on the conductive heat transfer through the final roof. This is due to the limited shading effect of such elements over the roof. However, extruding the parapet to the full floor height showed slightly better performance, namely in summer. As shown in Figure 2, the average daily fabric gains in summer decreased from $50.1 \mathrm{~kW} / \mathrm{h}$ in the reference case to $46.4 \mathrm{~kW} / \mathrm{h}$. This means a reduction of $7 \%$ in summer heat gains through the top building roof. Table 2 summarises summer and wintertime protection status as a result of using the above-discussed protection measures of the temporary roof.
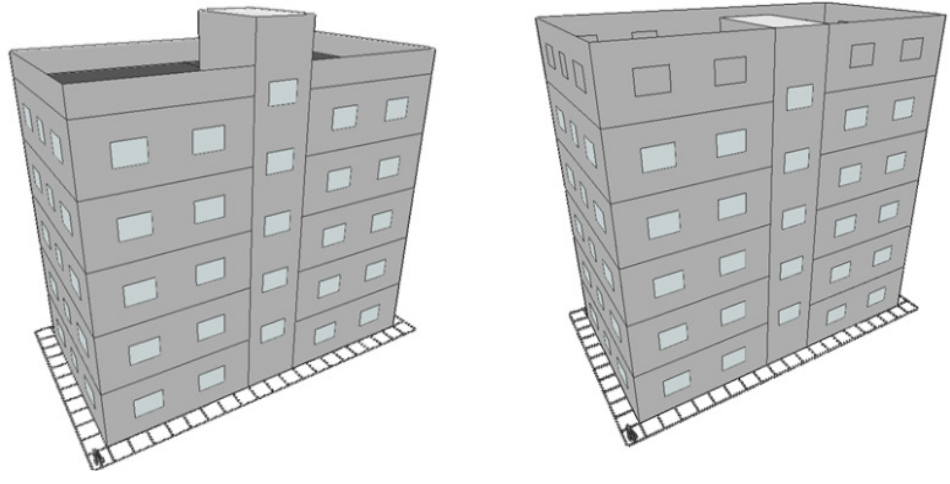

Figure 4. Roof shading using normal and extended parapets

\section{Combined strategies}

Finally, it is possible to maximise the observed positive effect of the above-discussed strategies using a combination of two or more strategies. Several possibilities exist here. However, the combination of the most two effective strategies is examined here. These are the use of pergolas and white coating of the roof. These two strategies are easy to apply as temporary insulation measures. As a result, a further reduction of summer fabric gains by about 5\% is observed. However, this is insignificant considering the additional cost of this strategy as discussed in the following section.

\section{A comparison between all protection strategies}

Table 2 compares the different proposed protection strategies in terms of their efficiency in summer and winter times. Although the hot climatic conditions are considered in this study, the additional benefit of heat loss reduction in winter is desirable too. Figure 5 shows the obtained fabric gain reduction per square metre for the top three protection strategies compared to their normalised initial cost $\left(\mathrm{USD} / \mathrm{m}^{2}\right)$. This cost has been estimated according to the local market price. The best scenario could be achieved in the case of the highest protection and the lowest cost. Figure 5 shows that this is not achievable because as protection, heat gain reduction, increases, the cost increases too. The highest cost is observed in the full insulation case, which includes the cost of thermal insulation, waterproofing, and top tiling. Costs of painting and shading strategies are almost the same, and are much lower than the rest of strategies (USD 1 and USD 1.5, respectively).

Thus, it is possible to notice that painting the roof or covering it with white foldable sheets; and the use of pergolas are the most effective measures. In both cases, a reduction of $38 \%$ in conductive heat transfer through the roof in summer could be observed 
compared to the unprotected modelling case. The tiling strategy offers higher protection but at much higher initial cost (USD $15 / \mathrm{m}^{2}$ ). This means that every reduction in a heat gain of $2 \mathrm{kWh}$ through the roof requires an initial cost of USD 100. However, a further energy consumption and payback analysis is required to find out if this cost could be recovered in a reasonable period of time or not.

Table 2. Summer and winter time performance summery of using the different proposed protection measures of the top roof

\begin{tabular}{ccc}
\hline Protection strategy & Reducing summer gains & Reducing winter losses \\
\hline Full insulation & $\sqrt{ }$ & $\sqrt{ }$ \\
White painting & $\sqrt{ }$ & $\times$ \\
White tiles & $\sqrt{ }$ & $\sqrt{ }$ \\
Dark tiles & $\sqrt{ }$ & $\sqrt{ }$ \\
Pergola & $\sqrt{ }$ & $\times$ \\
Normal parapet & $\times$ & $\times$ \\
High parapet & $\times$ & $\times$ \\
\hline
\end{tabular}

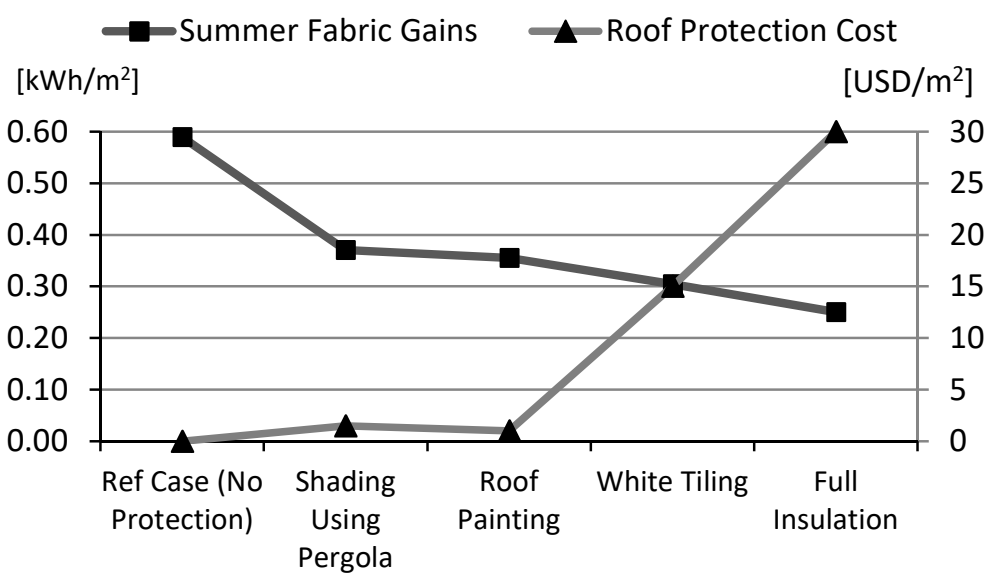

Figure 5. The effect of the top three protection strategies on the summer fabric gains $\left(\mathrm{kWh} / \mathrm{m}^{2}\right)$ compared to the estimated initial cost of each strategy (USD $\left./ \mathrm{m}^{2}\right)$

\section{CONCLUSIONS}

Sustainable architecture is a major component of the wider frame of sustainable development. One major aim of sustainable architecture to improve energy efficiency in buildings. This is achievable using several techniques including thermal insulation. Thermal insulation is not commonly used in the residential buildings of the Gaza Strip. Taking the final roof as a focus of this study, one main reason of not insulating this component is the local common practice of incremental housing construction. Multi-storey residential buildings are usually constructed according the occupants' current urgent need, leaving the "temporary" final rood uninsulated.

However, it is possible to notice that people use some techniques in treating this temporary roof, which affect its thermal performance in one way or another. The effect of these practices on occupants' thermal comfort has been analysed using computerised thermal modelling. The study found that it is possible to achieve competent thermal protection of the top roof compared to the layered thermal insulation using simple and reversible measures. These measures should be simple because they are temporary and should not be expensive. They should also be reversible to avoid the wintertime penalty 
of preventing the deserved solar radiation from reaching the roof. However, the wintertime penalty of using these protection measures has been found to be insignificant compared to the great advantage obtained in summertime.

Among the examined protection measures, covering the roof with white foldable sheets in addition to the use of pergolas has been found to be the most effective measures. In both cases, a reduction of $38 \%$ in conductive heat transfer through the roof in summer was observed compared to the unprotected modelling case. In addition, cost of these two strategies is relatively low compared to the rest of the strategies. The observed reduction of fabric heat gains in summer is a major advantage that would significantly reduce the cooling load attributable to the roofs located in hot climates. A further field survey is recommended to examine social acceptance and aesthetic impact of the different proposed roof protection measures.

\section{REFERENCES}

1. The World Commission on Environment and Development (WCED), Our Common Future, http://www.un-documents.net/wced-ocf.htm, [Accessed: 02-August-2016]

2. Edwards, B. and Hyett, P., Rough Guide to Sustainability, RIBA, London, 2002.

3. Arakawa, J. and Akimoto, K., Assessment of the Japanese Energy Efficiency Standards Program, Journal of Sustainable Development of Energy, Water and Environment Systems, Vol. 3, No. 1, pp 66-78, 2015, http://dx.doi.org/10.13044/j.sdewes.2015.03.0005

4. Szokolay, S. V., Introduction to Architectural Science: The Basis of Sustainable Design, Architectural Press, Oxford, UK, 2004.

5. Smith, P., Architecture in a Climate of Change: A Guide to Sustainable Design ( $2^{\text {nd }}$ ed.), Architectural Press, Oxford, UK, 2005.

6. Kumar, A. and Suman, B. M., Experimental Evaluation of Insulation Materials for Walls and Roofs and their Impact on Indoor Thermal Comfort under Composite Climate, Building and Environment, Vol. 59, pp 635-643, 2013, https://doi.org/10.1016/j.buildenv.2012.09.023

7. Asfour, O. and Kandeel, E., The Potential of Thermal Insulation as an Energy-Efficient Design Strategy in the Gaza Strip, Journal of Engineering Research and Technology, Vol. 1, No. 4, pp 117-125, 2014.

8. Jim, C. Y., Building Thermal-Insulation Effect on Ambient and Indoor Thermal Performance of Green Roofs, Ecological Engineering, Vol. 69, pp 265-275, 2014, https://doi.org/10.1016/j.ecoleng.2014.04.016

9. Brito Filho, J. P. and Oliveira Santos, T. V., Thermal Analysis of Roofs with Thermal Insulation Layer and Reflective Coatings in Subtropical and Equatorial Climate Regions in Brazil, Energy and Buildings, Vol. 84, pp 466-474, 2014, https://doi.org/10.1016/j.enbuild.2014.08.042

10. Yew, M. C., Ramli Sulong, N. H., Chong, W. T., Poh, S. C., Ang, B. C. and Tan, K. H., Integration of Thermal Insulation Coating and Moving-air-cavity in a Cool Roof System for Attic Temperature Reduction, Energy Conversion and Management, Vol. 75, pp 241-248, 2013, https://doi.org/10.1016/j.enconman.2013.06.024

11. Alrashed, F. and Asif, M., Trends in Residential Energy Consumption in Saudi Arabia with Particular Reference to the Eastern Province, Journal of Sustainable Development of Energy, Water and Environment Systems, Vol. 2, No. 4, pp 376-387, 2014, http://dx.doi.org/10.13044/j.sdewes.2014.02.0030

12. Tettey, U. Y. A., Dodoo, A. and Gustavsson, L., Effects of Different Insulation Materials on Primary Energy and $\mathrm{CO}_{2}$ Emission of a Multi-Storey Residential Building, Energy and Buildings, Vol. 82, pp 369-377, 2014, https://doi.org/10.1016/j.enbuild.2014.07.009 
13. Bevilacqua, P., Mazzeo, D., Bruno, R. and Arcuri, N., Experimental Investigation of the Thermal Performances of an Extensive Green Roof in the Mediterranean Area, Energy and Buildings, Vol. 122, pp 63-79, 2016, https://doi.org/10.1016/j.enbuild.2016.03.062

14. Mumtaz, P., Housing Finance, UN-HABITAT, UNESCAP, Thailand, 2008.

15. PCBS, Palestinian Central Bureau of Statistics, Summary of Demographic Indicators in the Palestine by Region, http://www.pcbs.gov.ps/Portals/_Rainbow/Documents/DEMO-2016-A.htm, [Accessed: 07-October-2016]

16. Palestinian Central Bureau of Statistics (PCBS), Conditions of Palestinians Residing in Palestine, Ramallah, 2013.

17. Asfour, O. S., Towards an Effective Strategy to Cope with Housing Land Scarcity in the Gaza Strip as a Sustainable Development Priority, Habitat International, Vol. 36, No. 2, pp 295-303, 2012, https://doi.org/10.1016/j.habitatint.2011.10.005

18. Ramamurthy, P., Sun, T., Rule, K. and Bou-Zeid, E., The Joint Influence of Albedo and Insulation on Roof Performance: A Modelling Study, Energy and Buildings, Vol. 102, pp 317-327, 2015, https://doi.org/10.1016/j.enbuild.2015.06.005

19. Arumugam, R. S., Garg, V., Ram, V. V. and Bhatia, A., Optimizing Roof Insulation for Roofs with High Albedo Coating and Radiant Barriers in India, Journal of Building Engineering, Vol. 2, pp 52-58, 2015, https://doi.org/10.1016/j.jobe.2015.04.004 Autodesk Ecotect

Analysis, http://www.autodesk.com.br/adsk/servlet/pc/index?siteID=1157326\&id=15362628, [Accessed: 07-October-2016]

21. Moore, F., Environmental Control Systems: Heating Cooling Lighting, McGraw-Hill, New York, USA, 1993. 